\title{
USING EXPERIMENTAL DESIGN TO DETERMINE THE WEAR RESISTANCE OF THE PADDED LAYERS BY FCAW
}

\author{
R. Bęczkowski", P. Kordas ${ }^{* *}$, S. Parzych ${ }^{* * *}$
}

\begin{abstract}
The paper presents the results of the experimental analysis of the parameters of the process of the flux cored arc welding (FCAW). Two-level Factorial Design for analysis was used. The coefficients of the regression equation concerning the influence of technological parameters such as current intensity I [A] and welding velocity $V s[\mathrm{~cm} / \mathrm{min}]$, the distance between the contact tip and the tip of the electrode Le [mm] on the loss of mass with comparison with their hardness were determined.
\end{abstract}

\section{Keywords: wear, Fe-Cr-C-V-W, FCAW, DOE}

\section{Introduction}

A huge progress in welding, metallurgy and material science ensures the possibility of using better metallic materials that are able to move working parameters higher and higher and to increase lifetimes of machines and their equipment. In order to utilize properties of these materials, the problem of wear should be considered at the design stage of the production and exploitation of machines. One of the effective way to suppress an extensive wear is to develop a welding technology of cladding materials with hard particle in the structure and special properties made by the flux cored arc welding (FCAW) in single layer (Adamiak et al., 2010 and Bęczkowski et al., 2015 and Bęczkowski et al., 2017 and Gucwa et al., 2014 and Gucwa et al., 2015). Chotěborský et al. (2011) tested cladding technology without preheating before cladding and with air cooling after process. Pernis et al. (2013) checked a pulsed power source, and the application of the plasma method was described by Bober et al. (2016).

Both cladding and thermal spraying technologies are widely applied to fabricate wear resistance surface layers. The layers fabricated on substrate materials may contain in near surface areas primary complex carbides or other phases having hardness up to 3000 HV (Bober et al., 2016).

Regardless of the opportunities offered by modern materials that increase surface properties, the wear of parts cannot be completely avoided and it always affects exploitation costs. From an economic point of view, it is most profitable to eliminate any friction couple of the device.

Use of modern surface layer materials cannot ensure that the resulting layers will be free of welding imperfections. These imperfections are classified in three permissible levels from the highest (level B), through the medium (level C), to the lowest (level D) (Bęczkowski, 2017).

One of the most important problem in welding protect surface technologies is to properly determine sets of parameters affecting the quality and properties of the layers. Knowledge on the impact of parameter settings changes gives a chance to obtain layers of different microstructure, hardness and surface without imperfections (Bęczkowski et al., 2016).

\footnotetext{
* Robert Bęczkowski, PhD.: DRB, Zagajnikowa 8, 98 330, Pajęczno; PL, robert.beczkowski@gmail.com

** Piotr Kordas, MSc.:Institute of Mechanical Technology, Technical University of Czestochowa; Armii Krajowej Street 21; 42 201,Częstochowa; PL, kordas@wimii.pcz.pl

*** Sławomir Parzych, PhD.:Institute of Materials Engineering, Cracow University of Technology; Warszawska St. 24; 31 155 Krakow; PL, slawomir.parzych@mech.pk.edu.pl
} 


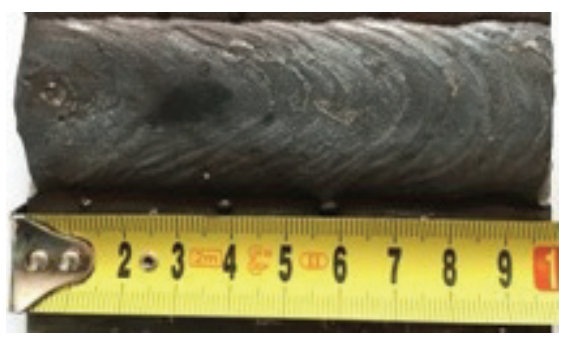

Fig. 1: The view of specimen of the clad surfacing

Cladding technologies can be used to build new layers as well as to rebuild the surface after wear in different industry sector. It is practically possible to rebuild the properties of the basic material and improve the properties of the contact layer. Cladding technologies allows for the construction of layers having small thickness. Furthermore, through adaptation of multi-run technology the thickness of the layer is not limited. The hardness of wear-resistant layers depends on the used materials and welding techniques. Particularly in core materials there is the possibility of put in hard carbides to the core of the wire (Gucwa et al., 2015, and Bober et al., 2016).

Generally, wear of material resistance depends on two factors: hardness and structure. A multi-parameter analysis of the processing effect on the end result. Is usually inconvenient and takes a lot of time. It is profitable to develop a study plan that limits to the minimum necessary the number of experiments that can make dependable results. Such possibility is provided by experience planning of experiments based on statistical programs that optimize the number of necessary trials and supports the statistical analysis of the received results. The $2 \mathrm{k}$ plan are readily used for this purpose (Kordas, 2017).

\section{Methods}

The material used for surface cladding experiment was S235JR type steel with the thickness of $10 \mathrm{~mm}$. The surface cladding process was carried out by using the 135 method. A weld pool was protected by the ( $82 \% \mathrm{Ar}, 18 \% \mathrm{CO}_{2}$ ) gas mixture. The cored wire with a chemical composition of: Fe-3.8C-22Cr-0.8V$0.8 \mathrm{~W}$ (wt \%); and a diameter of $1.2 \mathrm{~mm}$, was used. Fig 1 presented view of the surface one of the specimen.

The $2 \mathrm{k}$ plan has been used in the context of the influence of technological parameters on the wear of surfacing clad surface layer. Variable parameters: $\mathrm{x}_{1}$-the distance between the contact tip and the material Le $[\mathrm{mm}]$, range of variation $\langle 20,30\rangle, \mathrm{x}_{2}$-current intensity I [A], $\left.<213,277\right\rangle, \mathrm{x}_{3}$-welding velocity $\mathrm{Vs}[\mathrm{cm} / \mathrm{min}],<5,11>$.A knowledge on the ranges of variability of technological parameters allows determining the central value and unit of variation for each parameter $(1,2)$ :

$$
\begin{aligned}
& x_{i 0}=\frac{x_{\text {imax }}+x_{\text {imin }}}{2} \\
& \Delta x_{i}=\frac{x_{\text {imax }}-x_{\text {imin }}}{2}
\end{aligned}
$$

where: $\mathrm{i}$ - variable number, $\mathrm{x}_{\mathrm{imax}}, \mathrm{x}_{\mathrm{imin}}-$ maximum and minimum value $\mathrm{i}$-this input factor in variable range.

The experimental plan $2 \mathrm{k}$ consists in the planning matrix for the experiment used $(\mathrm{N}=8)$ based on the matrix experiment $X$, where is received in coded $(+1,-1)$ and encoded value:

$$
X=\left[\begin{array}{cccc}
1 & 20 & 213 & 5 \\
1 & 30 & 213 & 5 \\
1 & 20 & 277 & 5 \\
1 & 30 & 277 & 5 \\
1 & 20 & 213 & 11 \\
1 & 30 & 213 & 11 \\
1 & 20 & 277 & 11 \\
1 & 30 & 277 & 11
\end{array}\right] \quad X=\left[\begin{array}{cccc}
1 & -1 & -1 & -1 \\
1 & +1 & -1 & -1 \\
1 & -1 & +1 & -1 \\
1 & +1 & +1 & -1 \\
1 & -1 & -1 & +1 \\
1 & +1 & -1 & +1 \\
1 & -1 & +1 & +1 \\
1 & +1 & +1 & +1
\end{array}\right]
$$

Then changed natural variable for encoded variable using formula (3): 


$$
\mathrm{x}_{\mathrm{i}}^{*}=\frac{\mathrm{x}_{\mathrm{i}}-\mathrm{x}_{\mathrm{i} 0}}{\Delta \mathrm{x}_{\mathrm{i}}}
$$

Then the matrix of regression coefficients is built in this way:

$$
\begin{gathered}
B=\left(X^{\mathrm{T}} \mathrm{X}\right)^{-1} \mathrm{X}^{\mathrm{T}} \mathrm{B} \\
\mathrm{B}=\left(\mathrm{X}^{\mathrm{T}} \mathrm{X}\right)^{-1} \mathrm{X}^{\mathrm{T}} \mathrm{Y}=\left[\begin{array}{llll}
\frac{1}{8} & 0 & 0 & 0 \\
0 & \frac{1}{8} & 0 & 0 \\
0 & 0 & \frac{1}{8} & 0 \\
0 & 0 & 0 & \frac{1}{8}
\end{array}\right] \times\left[\begin{array}{cccccccc}
1 & 1 & 1 & 1 & 1 & 1 & 1 & 1 \\
-1 & +1 & -1 & +1 & -1 & +1 & -1 & +1 \\
-1 & -1 & +1 & +1 & -1 & -1 & +1 & +1 \\
-1 & -1 & -1 & -1 & +1 & +1 & +1 & +1
\end{array}\right] \times\left[\begin{array}{l}
\mathrm{y}_{1} \\
\mathrm{y}_{2} \\
\mathrm{y}_{3} \\
y_{4} \\
y_{5} \\
y_{6} \\
y_{7} \\
y_{8}
\end{array}\right]=\left[\begin{array}{l}
b_{0} \\
b_{1} \\
b_{2} \\
b_{3}
\end{array}\right]
\end{gathered}
$$

The values of the regression coefficients should be substituted to equation of the mathematical model in this way:

$$
y=b_{0}+b_{1} x_{1}^{\cdot}+b_{2} x_{2}^{*}+b_{3} x_{3}^{\cdot}
$$

After decoding the encoded variables, model of the mathematical equation was obtained:

$$
y=b_{0}+b_{1}\left(\frac{x_{1}-x_{10}}{\Delta x_{1}}\right)+b_{2}\left(\frac{x_{2}-x_{20}}{\Delta x_{2}}\right)+b_{3}\left(\frac{x_{3}-x_{30}}{\Delta x_{3}}\right)
$$

An example of a loss of weight according to the average hardness is shown in Fig. 2.

The lowest weight loss (Lw) was achieved for sample 4 (Le $=30 \mathrm{~mm}$; $=277 \mathrm{~A} ; \mathrm{Vs}=5 \mathrm{~cm} / \mathrm{min}) \mathrm{having}$ the hardness of $595 \mathrm{HV} 10$. On the other hand, the highest weight loss (Lw) was achieved for sample 7 $(\mathrm{Le}=20 \mathrm{~mm} ; \mathrm{I}=277 \mathrm{~A} ; \mathrm{Vs}=11 \mathrm{~cm} / \mathrm{min})$ having the hardness $554 \mathrm{HV} 10$. According to experimental procedure the regression coefficients (b0, b1, b2, b3) according the equation (4), were calculated.

After substituted the values of the regression coefficients to equation (5), mathematical model was obtained (7):

$$
y_{1}=L_{w}=0,03675-0,00475 x_{1}^{*}-0,0015 x_{2}^{*}+0,00575 x_{3}^{*}
$$

Then the encoded variable, according to equation (6), were decoded. The mathematical model was received (8):

$$
\mathrm{y}_{1}=\mathrm{L}_{\mathrm{w}}=0,03675-0,00475\left(\frac{\mathrm{Le}-25}{5}\right)-0,0015\left(\frac{\mathrm{I}-245}{32}\right)+0,00575\left(\frac{\mathrm{V}_{\mathrm{s}}-8}{3}\right)
$$

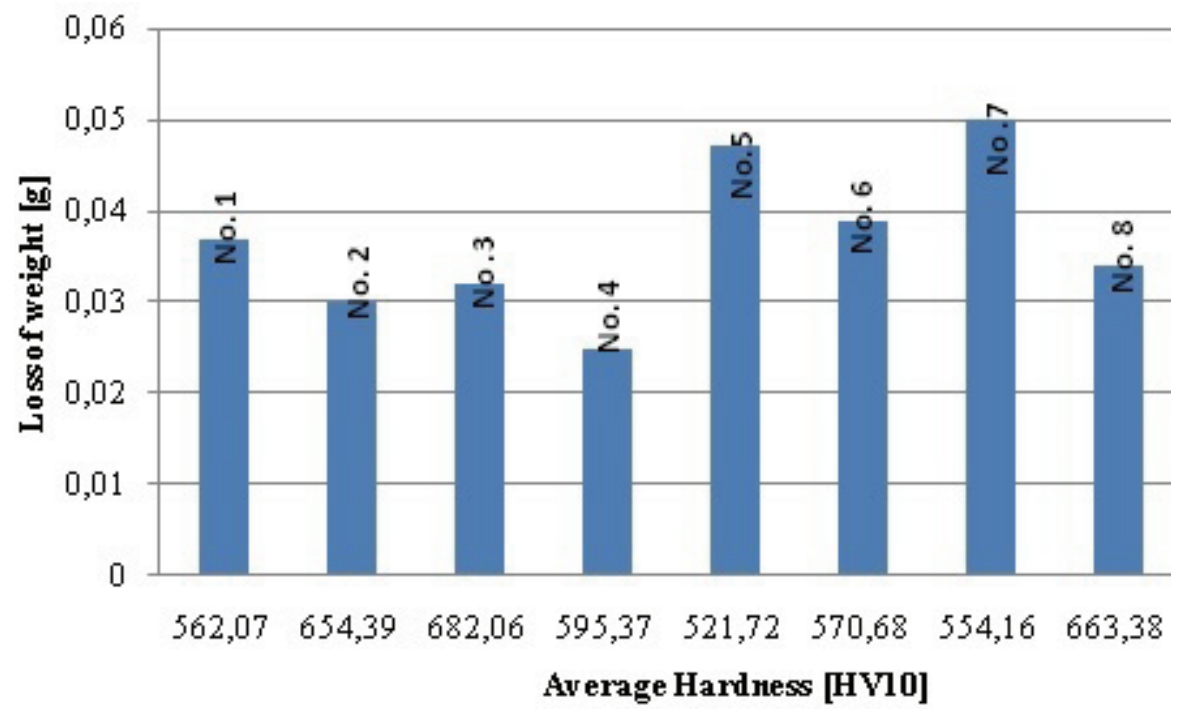

Fig. 2: Dependence weight loss to average hardness 
Relative errors of average hardness between actual value and value obtained from mathematical model are for the following samples (Sample No.) at the level: (1)-0.68\%, (2)-7.5\%, (3)-7.03\%, (4)-1\%, (5)$3.72 \%,(6)-0.64 \%,(7)-8.5 \%,(8)-6.62 \%$.

\section{Conclusions}

By using the $2 \mathrm{k}$ experiment scheme, a precise determination of the impact of the process parameters on the final properties, can be carried out. It also allows building a mathematical model described by the linear equation. The built-in model describing the weight loss does not suffer from large errors. All regression coefficients are at a similar level.

Weight loss decreases as the length of the free wire and the welding intensity increases. The increase of the weight loss o is due to the increase in cladding speed.

The built-in mathematical model was designed to optimize the clad process with use flux cored arc welding (FCAW) for the Fe-Cr-C-V-W type wire.

\section{References}

Adamiak, M., Górka, J. and Kik, T. (2010) Structure analysis of welded joints of wear resistant plate and constructional steel, Archives of Materials Science and Engineering, 56, 2, pp. 108-114.

Bęczkowski, R. (2017) Repair Welding of the Massive Cast. Archives of Foundry Engineering, 17(2), pp.5-8.

Bęczkowski, R. and Gucwa, M. (2016) Defects Appearing in the Surfacing Layers of Abrasion Resistance. Archives of Foundry Engineering, 16(4) pp. 23-28. DOI: 10.1515/afe-2016-0077.

Bęczkowski, R., Gucwa M., Wróbel, J. and Kulawik, A. (2015) The Impact of the Bead Width on the Properties of the Anti-Abrasion Surfacing Weld. (ICNAAM2015) AIP Conf. Proc. 1738, 480095-1-480095-4; DOI: 10.1063/1.4952331.

Bęczkowski, R., Wróbel, J. and Kulawik, A. (2017) The Use of Numerical Modelling to Determine the Conditions of Regeneration of Medium Carbon Steel. Arch. Metall. Mater. 62, 4, pp. 2223-2230, DOI: 10.1515/amm-20170328.

Bober, M. and Senkara, J. (2016) Comparative tests of plasma-surfaced nickel layers with chromium and titanium carbides, Welding International, 30(2), pp.107-111, DOI:10.1080/09507116.2014.937616.

Chotěborský, R., Hrabě, P., Muller, M., Sawkova, J. and Jirka, M. (2011) Abrasive wear of high chromium Fe-Cr-C hardfacing alloys, Research in Agricultural Engineering, 57, pp. 56-62.

Gucwa, M. and Bęczkowski, R., (2014) The effect of heat input on the geometric properties of welded joints, Archives of Foundry Engineering, 14(spec. 1), pp.127-130.

Gucwa, M., Winczek, J., Bęczkowski, R. and Dośpiał M. (2016) Structure and Properties of Coatings Made with Self Shielded Cored Wire. Archives of Foundry Engineering, 16(3), pp.39-42.

Kordas, P. (2017) Application of cored wires for production slide plates in the mining industry, Master thesis, Częstochowa University of Technology.

Pernis, I., Kasala, J. and Žabecká, D. (2013) Resistance of weldclads made by flux-cored arc welding technology against erosive wear. Metalurgija 52(3), pp. 352-354 